\title{
Desigualdade espacial: a relação entre densidade populacional e renda domiciliar na cidade de Goiânia ${ }^{1}$
}

\section{Spacial inequality: the relationship between population density and gentrification in Goiânia}

\author{
Souto, Sara Lopes'; Brandstetter, Maria Carolina G. Oliveira² \\ ' Escola de Engenharia Civil e Ambiental, Universidade Federal de Goiás, \\ Avenida Universitária, 1488, Setor Leste Universitário, Goiânia-GO, e-mail: \\ sara_@hotmail.com \\ ${ }^{2}$ Escola de Engenharia Civil e Ambiental, Universidade Federal de Goiás, e- \\ mail: mariacarolina.brands@gmail.com
}

\section{RESUMO}

A discussão do papel das áreas urbanas na promoção do desenvolvimento sustentável é imprescindível. A forma urbana entra nessa conjuntura como um fator determinante para a concepção de cidades que promovam crescimento econômico, equidade social e redução dos impactos ambientais. Este trabalho tem como objetivo discutir conceitos relacionados à forma urbana e sustentabilidade e entender qual a relação entre densidade populacional e renda domiciliar nesses espaços por meio de um estudo de caso na cidade de Goiânia. Valendo-se de um levantamento bibliográfico e da análise dos dados e mapas temáticos produzidos pelo último censo populacional, foi possível constatar o processo de gentrificação de áreas mais adensadas, caracterizados como processos de segregação sócio espacial dentro da metrópole goiana. O trabalho conclui buscando contribuir com as discussões relativas ao planejamento urbano e corroborando o questionamento sobre cidade compacta e realidade urbana sustentável.

Palavras-chave: espaço urbano, densidade populacional, renda domiciliar.

\begin{abstract}
The discussion of urban areas in promoting sustainable development is imperative. The urban form is a determining factor for cities design that promote economic growth, social equity and reduction of environmental impacts. This work aims to discuss concepts related to urban form and sustainability and to understand the relationship between density and income in these spaces. A case study was carried out at the city of Goiânia. Using a bibliographical survey and data analysis of thematic maps produced by the last population census, it was possible to verify the gentrification process of denser areas in the metropolis of Goiás. The paper concludes by seeking to contribute to discussions related to urban planning and corroborating the questioning about compact city and sustainable urban reality.
\end{abstract}

\footnotetext{
${ }^{1}$ SOUTO, Sara Lopes; BRANDSTETTER, Maria Carolina G. O. Desigualdade espacial: a relação entre densidade populacional e renda domiciliar na cidade de Goiânia. In: II SIMPÓSIO NACIONAL DE GESTÃO E ENGENHARIA URBANA: SINGEURB, 2019, São Paulo. Anais... Porto Alegre: ANTAC, 2019.
} 
Keywords: urban environment, population density, gentrification.

\section{INTRODUÇÃO}

A segunda metade do Século XX foi marcada pela inversão campo/cidade da população mundial. Atualmente, no mundo, pouco mais de $54 \%$ dos habitantes do planeta vivem em cidades. No Brasil, essa porcentagem é ainda mais expressiva, $82,2 \%$ da população vive em cidades e projeções indicam que este número pode chegar a 91,0\% até 2050 (ONU, 2014). Em alguns países, entre estes os Brasil, este processo de urbanização se deu de maneira rápida, desordenada e sem a presença do poder público (BARBOSA, 2008; CANO, 1989).

Na década de 1970, já em face de uma realidade altamente urbanizada e da evidente crise socioambiental, a Organização das Nações Unidas inicia as discussões acerca de uma nova forma de se promover o crescimento econômico associado à equidade social e à preservação ambiental, o Desenvolvimento Sustentável (BARBOSA, 2008; SACHS, 1993).

Dado o contexto mundial altamente urbanizado, o conceito de sustentabilidade inevitavelmente esbarrou nas questões que envolvem o meio urbano, evidenciando a necessidade de se pensar e conceber este espaço dentro dos preceitos do desenvolvimento sustentável (BARBOSA, 2008). Diversos aspectos contribuem para a promoção da sustentabilidade urbana, dentre estes está a morfologia urbana, que se traduz através da densidade, compacidade, vias, edifícios e espaços públicos (SILVA; ROMERO, 2015; DEMPSEY; BROWN; BRAMLEY, 2012).

Neste contexto, este trabalho tem por objetivo discutir conceitos relacionados à forma urbana e sustentabilidade, buscando uma maior compreensão da relação entre densidade populacional e renda domiciliar nesses espaços, por meio de um estudo de caso realizado na cidade de Goiânia.

\section{SÍNTESE BIBLIOGRÁFICA}

A promoção da cidade compacta como uma alternativa mais sustentável da forma urbana é compartilhada por vários autores (DEMPSEY; BROWN; BRAMLEY, 2012; RÉRAT, 2012; SILVA; ROMERO, 2015; CHENG, 2010; HENG; MALONE-LEE, 2010).

A favor dessa proposição estão os argumentos de que uma forma urbana compacta, sobretudo associada a funções mistas do solo, viabiliza deslocamentos pedonais e por bicicleta e torna financeiramente mais interessante a promoção do transporte público e implementação de infraestruturas urbanas como redes de água, energia e esgoto. Alguns autores consideram esta forma de cidade mais democrática, por permitir uma parcela maior da população melhor acesso às facilidades urbanas (SILVA; ROMERO, 2015; CHENG, 2010; DEMPSEY; BROWN; BRAMLEY, 2012).

Apesar de desejável do ponto de vista da sustentabilidade, observa-se que as cidades, sobretudo em suas periferias, tendem a crescer de forma dispersa (RÍOS; ROCCA, 2014). Essa tendência é explicada por Silva e Romero (2015) como resultado da falta de políticas públicas que controlem atores especulativos imobiliários e invasões. Rérat (2012) argumenta que boa parte do crescimento disperso do perímetro urbano se deve ao desejo de famílias morarem em vizinhanças menos densas em busca de espaço, privacidade e melhores condições ambientais como menor polvição sonora e do ar.

Ríos e Rocca (2014) atribuem a expansão crescente e difusa do perímetro urbano das cidades latino-americanas à força do capital imobiliário sobre as políticas de uso e ocupação do solo, além da fragilidade do transporte público, dificuldade de acessibilidade, exclusão social, carência de infraestruturas básicas e a consequente contaminação do solo e da água.

O modelo de cidade compacta também não é livre de críticas. Rérat (2012) explora as desvantagens de cidades com altas densidades populacionais: o conflito na oferta e demanda, pois o potencial de densificação é pequeno para conter a expansão urbana, os custos de se regenerar e densificar áreas urbanas que seriam pagos através da gentrificação 
destes espaços, além da geração de congestionamentos e polvição. Heng e Malone-Lee (2010) também salientam o barulho, congestionamento, polvição localizada, percepção negativa causada pela superlotação urbana e falta de privacidade.

Percebe-se que apesar da forte corrente que defende a forma compacta da cidade como a mais sustentável, não há um consenso no meio científico sobre as vantagens atreladas ao desenvolvimento desse modelo de cidade. Nesse contexto fica clara a necessidade de se aprofundar a discussão de fenômenos como a desigualdade espacial e a relação entre densidade populacional e renda domiciliar dentro do espaço urbano.

\section{MÉTODO DE PESQUISA}

Para atingir o objetivo proposto, optou-se pela realização de um estudo de caso na cidade de Goiânia. Uma primeira etapa foi realizada para caracterizar a evolução populacional e gestão territorial da cidade, por meio de referencial bibliográfico. Posteriormente buscou-se entender a relação entre renda domiciliar e densidade populacional, por meio de mapas temáticos das áreas de ponderação da cidade. As áreas de ponderação (AP) são definidas como o menor recorte geográfico para se levantar inferências estatísticas populacionais confiáveis baseadas em dados amostrais (CORTEZ; MONTENEGRO; BRITO, 2012).

Por ser um município de mais de 190 mil habitantes, foi facultada à prefeitura de Goiânia a definição das AP. Esta delimitou $43 \mathrm{AP}$ seguindo os critérios estabelecidos pelo Instituto Brasileiro de Geografia e Estatística (IBGE): cada setor censitário poderia estar contido em apenas uma única AP, os setores deveriam ser contíguos e 400 era o número mínimo de domicílios particulares permanentes por AP (CORTEZ; MONTENEGRO; BRITO, 2012; IBGE, 2010). As análises consideraram a distribuição espacial das AP considerando população e número de domicílios particulares. A partir dos dados do censo demográfico (IBGE, 2010) foram obtidas as médias e medianas de renda por domicílio dentro das AP.

\section{RESULTADOS E DISCUSSÕES}

\subsection{Evolução da população e a gestão territorial na cidade de Goiânia}

O arquiteto-urbanista Attilio Corrêa Lima foi o responsável pelo projeto urbano de Goiânia (Figura 1), que mais tarde recebeu modificações do engenheiro-urbanista Armando Godoy (Figura 2). A cidade foi inicialmente pensada para atender a uma população de 50 mil pessoas distribuídas em quatro setores: central, norte, sul e oeste. O projeto de Corrêa Lima era aberto à expansão da cidade, mas Godoy pensava a cidade dentro de um perímetro fixo, sugerindo que o possível excedente populacional viesse a ser abrigado em cidadessatélites (DAHER, 2009; VIEIRA, 2012).

Figura 1 - Plano original da cidade de Goiânia proposto por Attilio Corrêa Lima

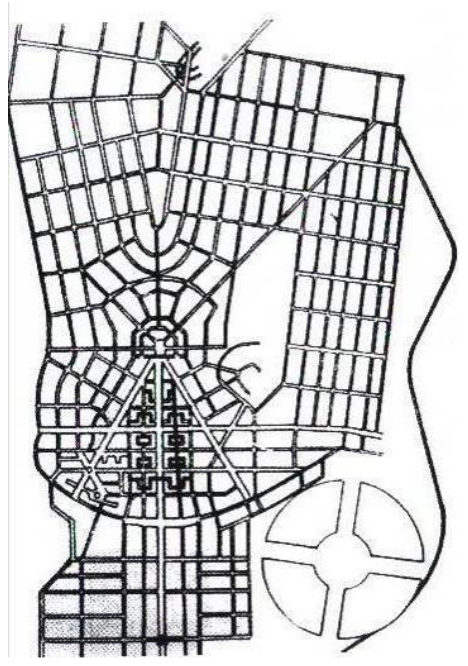

Fonte: Manso (2001)
Figura 2 - Plano definitivo do núcleo inicial de Goiânia proposto por Armando Godoy

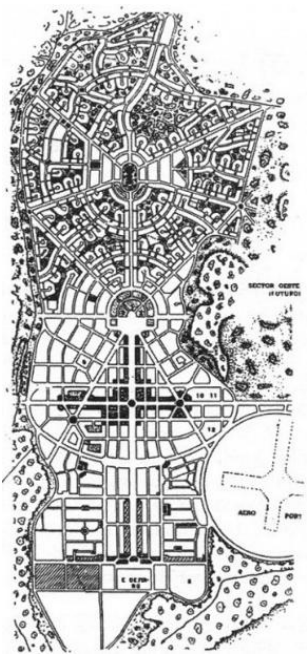

Fonte: Manso (2001) 
Segundo Daher (2009) o projeto inicial já previa a segregação funcional e de classes do espaço urbano. Os Setores Sul e Oeste seriam compostos por residências e comércio local.

No início da década de 60, Goiânia já contava com uma população três vezes maior que a planejada. Na década de 70 o crescimento populacional foi mais acentuado, chegando a 700 mil habitantes no ano de 1980. Hoje, estima-se que a capital tenha aproximadamente 1.495.705 habitantes e uma densidade demográfica média de 2.052, 17 hab/ $/ \mathrm{km}^{2}$, tornando-a o décimo município mais populoso do país (IBGE, 2018).

Segundo Vieira (2012, p.59) o projeto inicial propunha ao Estado "(...)organização administrativa e um regulamento para as construções da cidade, o primeiro com a finalidade de separar a cidade das influências políticas e especulativas e o segundo procurando definir o regulamento urbanístico." Entretanto, os construtores da cidade e detentores de grande parcela das terras em seus arredores, através de prestígio político, garantiram um importante papel para iniciativa privada na edificação da cidade desde sua concepção (UNES, 1998; VIEIRA, 2012).

Diante do intenso aumento populacional e de sua função estratégica, Goiânia, inicialmente planejada, teve acentuada a privatização de seu desenvolvimento, marcado pela especulação imobiliária, formação de vazios demográficos, formas desiguais de ocupação do solo (OLIVEIRA; CHAVEIRO, 2008; SILVA; PENA, 2012), além do fenômeno de gentrificação na região sul da cidade a partir da década de 80 (MARINHO, 2006).

\subsection{Relação entre renda domiciliar e densidade populacional na cidade de Goiânia}

Nas Figuras 3 e 4 observa-se a distribuição espacial das AP no município de Goiânia relacionadas à população e ao número de domicílios. As áreas territoriais das AP são significativamente menores nas regiões sul e central, sendo as maiores observadas nas demais periferias do município, com destaque para o norte e oeste.

Figura 3 - População total (em número de habitantes) por área de ponderação

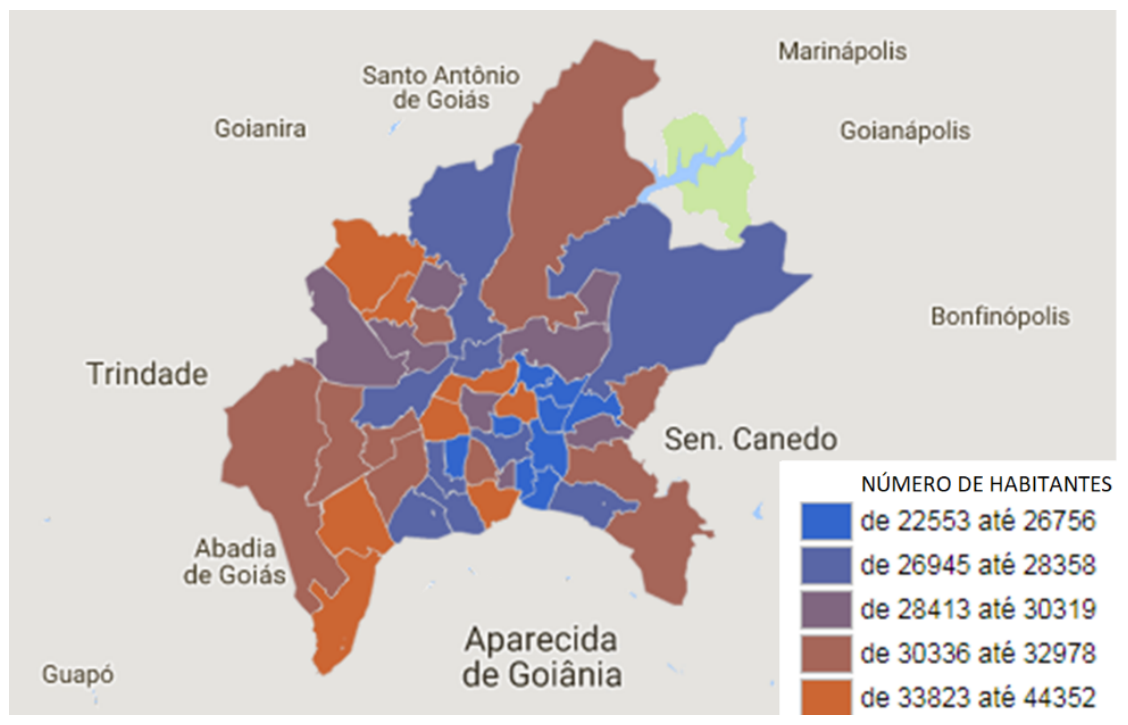

Fonte: Autores a partir de dados do IBGE (2010) 
Figura 4 - Número de domicílios particulares por área de ponderação

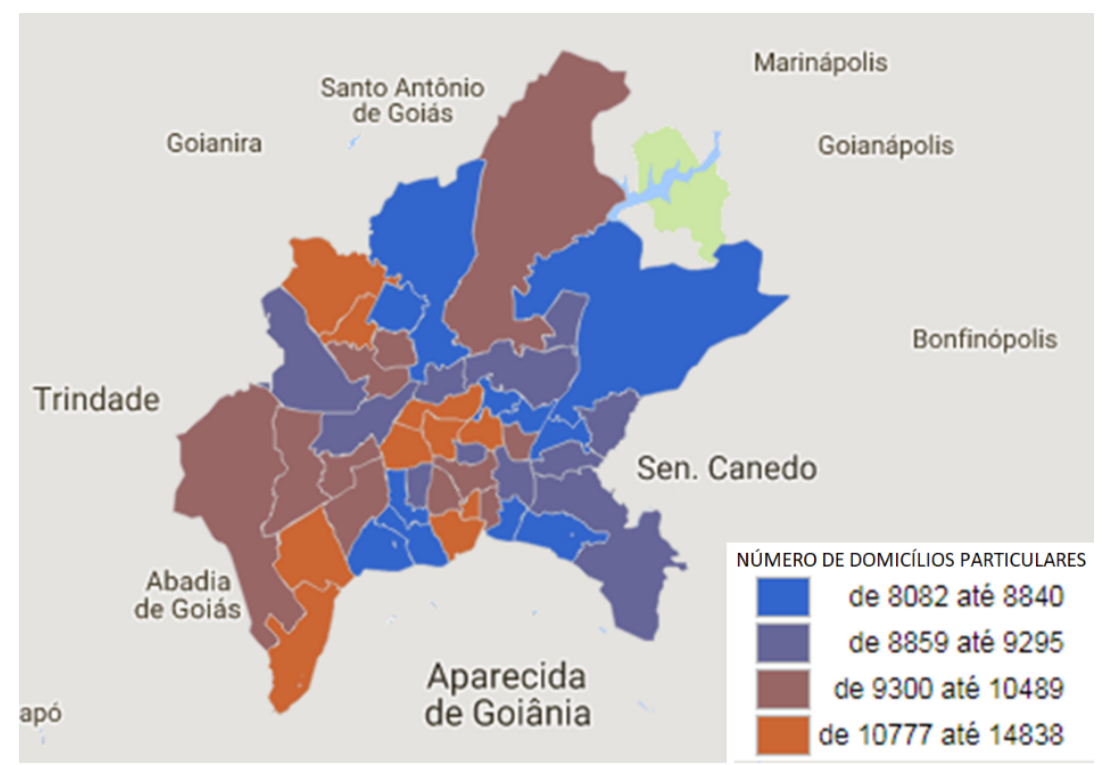

Fonte: Autores a partir de dados do IBGE (2010)

Constata-se que a magnitude da desproporção territorial não é observada no nível de número de domicílios, e menos ainda no nível de população absoluta. Não é observada uma relação direta de aumento da população ou domicílios à medida que se aumentam os territórios das AP. Este fenômeno pode ser explicado pelo fato das AP serem delimitadas a partir de um número mínimo de domicílios e buscando-se uma homogeneidade das características. Conclui-se a partir destes dois mapas que há, de fato, uma maior densidade populacional nas regiões central e sul do município.

Nas Figuras 5 e 6 nota-se que à medida que a renda média se eleva, cresce também a mediana. Entretanto, esse crescimento não segue a mesma taxa. Quanto maior a faixa de renda, maior é a taxa de crescimento de ambas, sendo a taxa de crescimento da média de renda maior que a da mediana, chegando ao ponto em que a renda média da AP mais rica quase dobra em relação a renda mediana da mesma AP. A diferença observada entre média e mediana está provavelmente relacionada a grandes desvios padrões que indicam significativas disparidades de poder aquisitivo dentro das AP.

Figura 5 - Relação entre renda domiciliar média e mediana

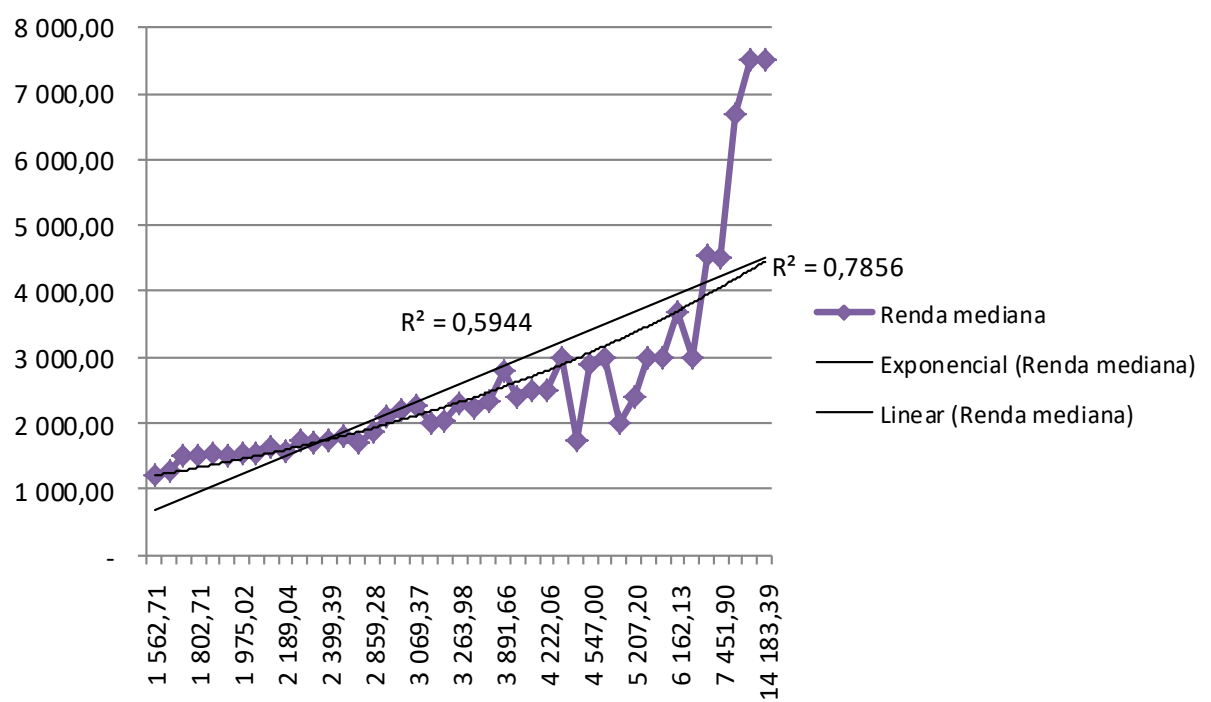

Fonte: Autores a partir de dados do IBGE (2010) 
Figura 6 - Renda domiciliar média e mediana por área de ponderação

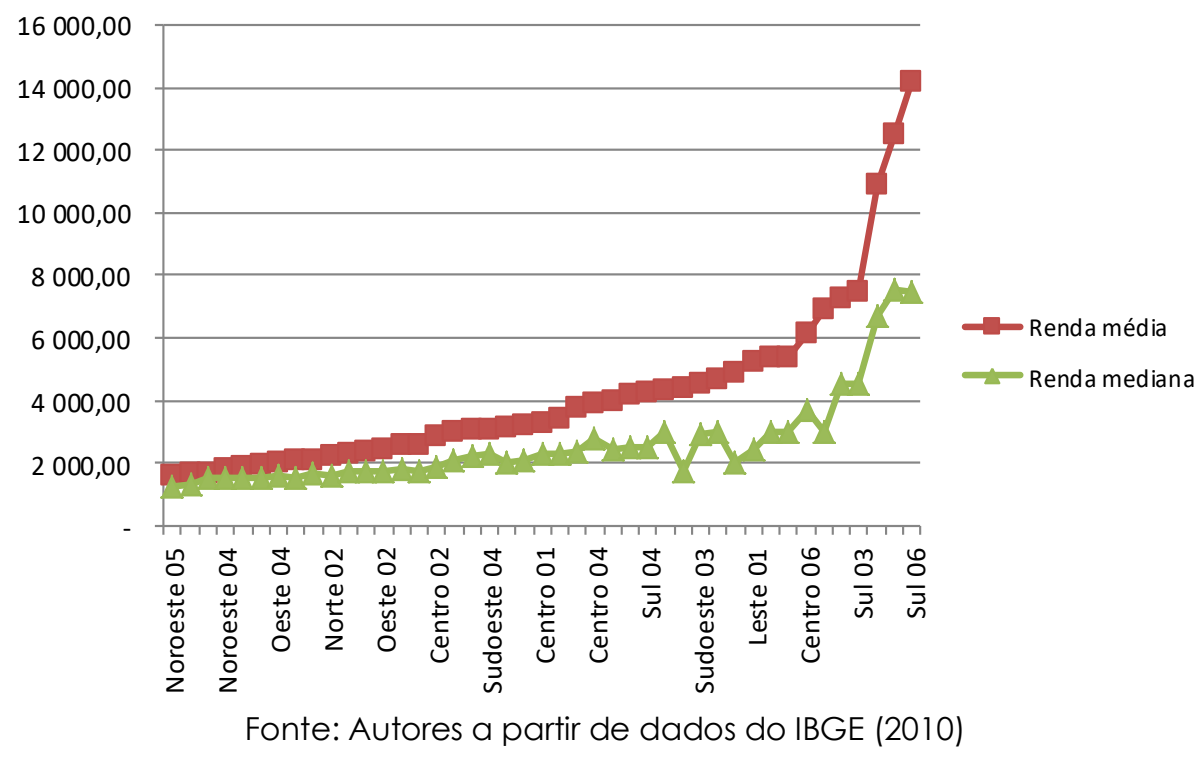

Uma vez que o dado de renda média apresenta uma distorção relativa à disparidade de renda populacional, escolheu-se fazer a análise da renda domiciliar mediana por área de ponderação. Na Figura 7 observa-se a segregação socioeconômica dentro do espaço urbano. Enquanto o centro-sul do município é caracterizado por rendas domiciliares medianas entre $R \$ 2300,00$ e $R \$ 7510,00$, a porção noroeste é marcada por rendas domiciliares medianas entre $R \$ 1210,00$ e $R \$ 2260,00$. Constata-se que há uma correspondência entre áreas menos adensadas do município como o centro-sul e poder aquisitivo mais elevado da população. Em contrapartida áreas mais adensadas como as APs localizadas à oeste do município correspondem a menores medianas de renda domiciliar.

Figura 7 - Mediana da renda domiciliar (unidade em reais) por área de ponderação

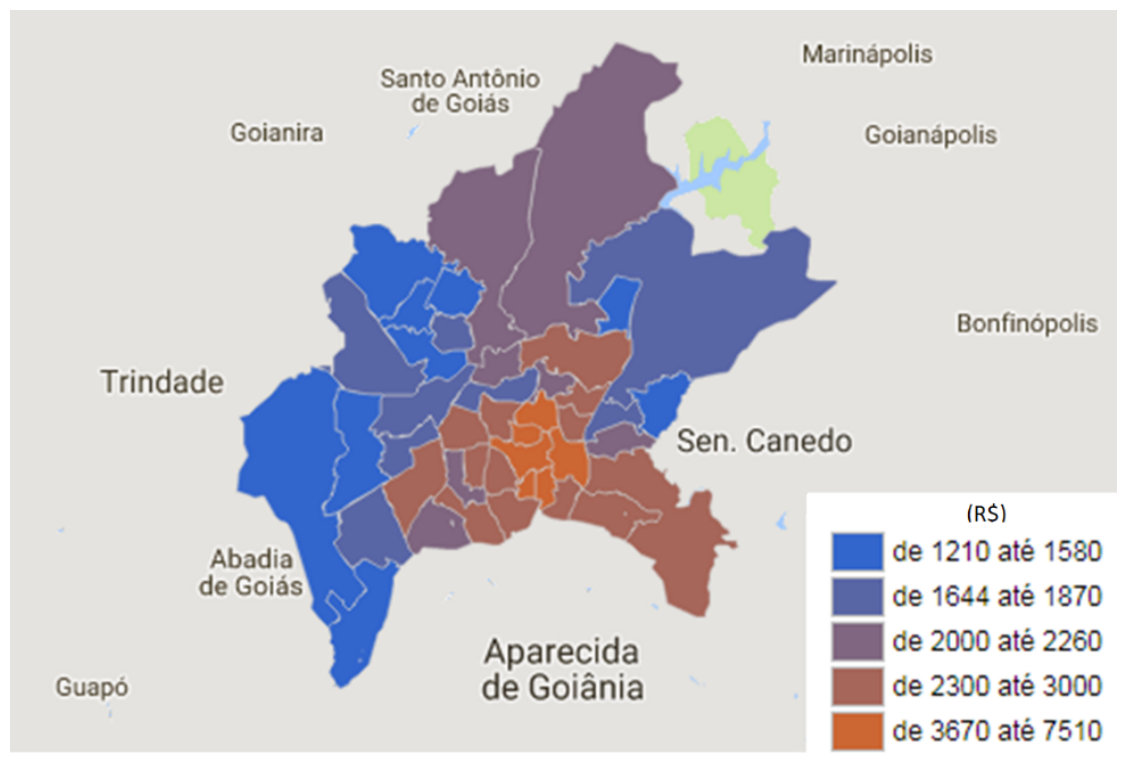

Fonte: Autores a partir de dados do IBGE (2010)

\section{CONCLUSÕES}

A população da cidade de Goiânia dobrou nas últimas quatro décadas e seu espaço urbano sofreu formas desiguais de ocupação e separação.

A cidade reproduz processos de segregação espacial típicos das metrópoles brasileiras. A 
partir deste estudo, foi possível observar neste município a gentrificação das áreas mais adensadas e com melhores infraestruturas urbanas.

Durante a realização do estudo, foi constatada uma disparidade significativa entre dados de renda média e renda mediana, levantando a hipótese de que valores médios de renda podem gerar distorções, devido às desigualdades de poder aquisitivo da população na cidade.

A partir deste trabalho identificou-se a necessidade de se explorar a relação renda domiciliar e densidade populacional em uma perspectiva metropolitana, levando-se em consideração as áreas urbanas conurbadas de outros municípios.

As análises permitiram corroborar o questionamento sobre em que medida a cidade compacta produz necessariamente uma realidade urbana sustentável do ponto de vista social.

\section{REFERÊNCIAS}

BARBOSA, G. S. O desafio do desenvolvimento sustentável. Revista Visões, v. 4, n. 1, p. 1-11, 2008.

CANO, W. Urbanização: sua crise e revisão de seu planejamento. Revista de Economia Política, v. 9, n. 1, p. 62-82, 1989.

CHENG, V. Understanding density and high density. Designing high-density cities for social and environmental sustainability, p. 3-17, 2010.

CORTEZ, B. F.; MONTENEGRO, F. M. T.; BRITO, J. de M. Censo demográfico 2010: definição das áreas de ponderação para o cálculo das estimativas provenientes do questionário da amostra. ENCONTRO NACIONAL DE ESTUDOS POPULACIONAIS, v. 28, p. 13, 2012.

DAHER, T. O projeto original de Goiânia. Revista da UFG, 2009.

DEMPSEY, N; BROWN, C; BRAMLEY, G. The key to sustainable urban development in UK cities? The influence of density on social sustainability. Progress in Planning, v. 77, n. 3, p. 89-141, 2012.

HENG, C. K; MALONE-LEE, L. C. Density and urban sustainability: An exploration of critical issues. Designing High-Density Cities For Social and Environmental Sustainability, 2010.

IBGE, Instituto Brasileiro de Geografia e Estatística. Censos Demográficos 2010 e Estatísticas 2018. Rio de Janeiro: IBGE.

MANSO, C. F. A. Goiânia: Uma Concepção Urbana e Moderna - Um Certo Olhar. Goiânia: Edição do autor, 2001.

MARINHO, C. B. Região Sul de Goiânia: um lugar valorizado na metrópole. GEOUSP: Espaço e Tempo (Online), n. 19, p. 113-129, 2006.

OLIVEIRA, A. F.; CHAVEIRO, E. F. Desigualdades sócio-espaciais, democracia e gestão metropolitana: análise do desempenho institucional em Goiânia (1997-2007). Boletim Goiano de Geografia, v. 28, n. 2, 2008.

ORGANIZAÇÃO DAS NAÇÕES UNIDAS, Department of Economic and Social Affairs, Population Division. World Urbanization Prospects. 2014. Disponível em: http://esa.un.org/wpp/Documentation/pdf/WPP2012_\%20KEY\%20FINDINGS.pdf. Acesso em: abril de 2019. 
RÉRAT, P. Housing, the compact city and sustainable development: Some insights from recent urban trends in Switzerland. International Journal of Housing Policy, v. 12, n. 2, p. 115-136, 2012.

RÍOS, L.; ROCCA, M. J. Reconfiguración del territorio y política territorial: dispersión y baja densidad en las áreas de crecimiento reciente de la ciudad de Tandil, Provincia de Buenos Aires. Territorios, [S.I.], n. 30, p. 109-126, jun. 2014. ISSN 2215-7484. Disponível em: doi:http://dx.doi.org/10.12804/territ30.2014.05. Acesso em: abril de 2019.

SACHS, I. Estratégias de Transição para do século XXI - Desenvolvimento e Meio Ambiente. São Paulo: Studio Nobel - Fundação para o desenvolvimento administrativo, 1993.

SILVA, G; ROMERO, M. Sustentabilidade urbana aplicada: Análise dos processos de dispersão, densidade e uso e ocupação do solo para a cidade de Cuiabá, Estado de Mato Grosso, Brasil. EURE (Santiago), v. 41, n. 122, p. 209-237, 2015.

SILVA, M. A. V.; PENA, R. F. A. Cidade, Cultura e a Disputa pelo Direito ao Espaço: segregação urbana das comunidades de terreiro na região metropolitana de Goiânia. Raega-O Espaço Geográfico em Análise, v. 24, 2012.

UNES, W. O esforço de interiorização do país e a construção de Goiânia. História Revista, v. 3, n. 1, p. 111-126, 1998.

VIEIRA, P. D. A. Attilio Corrêa Lima e o planejamento de Goiânia-um marco moderno na conquista do sertão brasileiro. URBANA, v. 4, n. 4, 2012. 